\title{
Adjustments to Cash Build-up when Retaining Dividends in the FCFE Valuation
}

\author{
João Marques Silva and José Azevedo Pereira \\ Instituto Universitário de Lisboa (ISCTE-IUL)Lisbon, Portugal \\ Email: joao.silva@iscte.pt,jpereira@iseg.ulisboa.pt
}

\begin{abstract}
Valuation based on DCF (Discounted Cash Flow) has been the dominant valuation procedure during the last decades. In spite of this dominance, enterprise valuation using the discounted FCF (Free Cash Flow) model has some practical drawbacks, since there is often some confusion on how to effectively use it. Commonly, the valuation procedures start by estimating future FCF figures from historical data, such as mean FCF, growth and retention ratio, alongside many other variables. These FCF forecasts are discounted at the cost of equity (FCFE - FCF to Equit1y) or the Weighted Average Cost of Capital WACC (FCFF FCF to Firm). Implicit in the above mentioned valuation procedures is the expectation that the company puts the free cash that it is generating to good use, yielding a value capable of rewarding appropriately the level of risk inherent in the way it used. In other words, the enterprise is not supposed to just shelve the cash generated or alternatively, investing it in bank accounts with returns below the equilibrium returns available in the market for the same level of risk. However, most of the times, the return rate isn't the same as initially expected, being either higher or lower than the market's expectation, with significant changes to the cash build-up on the company. This paper analyzes such changes and introduces a correction factor to the cash build-up.
\end{abstract}

Index Terms-Valuation, Free Cash Flow, Discounted Cash Flow, Reinvestment performance

\section{INTRODUCTION}

The essence of discounted cash flow valuation is simple; the asset is worth the expected cash flows it will generate, discounted to the reference date for the valuation exercise (normally, the day of the calculation). A survey article was written in [1], where it was stated that the earliest interest rate tables (use to discount value to the present) dated back to 1340 . However, financial mathematics can be traced to an earlier period - the writings of Fibonacci, in 1202. Later, in 1582, a Flemish mathematician, Simon Stevin wrote one of the first textbooks on finance, laying out the basis for calculating the present value [2]. It was only after 3 centuries that a civil engineer, A.M. Wellington [3] argued that the present value of future cash

Manuscript received July 1, 2017; revised August 21, 2017

We gratefully acknowledge financial support from FCT- Fundação para a Ciencia e Tecnologia (Portugal), national funding through research grant (UID/SOC/04521/2013). flows should be taken into account when calculating the up-front investment. The intellectual basis for discounted cash flow was described in both Bohm-Bawerk [4] (with a home purchase example with 20 annual instalment payments) and Marshall [5]. Finally, present value equations were developed for annuities, in order to assess the need to either buy new equipment or retain old equipment in [6].

The principles of modern valuation were consolidated in Irving Fisher's books [7],[8]. In these books, there were four alternative approaches for analyzing investments, namely choosing the investment that:

- had the highest present value at the market interest rate

- had the largest gap between benefits and cost in terms of present values

- had the highest "rate of return on sacrifice", above the market interest rate

- compared to the next most costly investment yielded a return in excess of the market rate

Note that the first two approaches represent the net present value rule, the third is the IRR - Internal Rate of Return approach and the last is the marginal rate of return approach. Later works from [9],[10] derived the IRR for an investment. Samuelson [11] compared the IRR and NPV (Net Present Value) approaches, arguing that rational investors should maximize NPV and not IRR.

The previously mentioned works and the publication of Joel Dean's reference book [12] on capital budgeting set the basis for the widespread use of the discounted cash flow approach into all business areas, aided by developments in portfolio theory. There are four main variants of discounted cash flow models, each with its own advantages and disadvantages. These are:

- Discounted cash flow with a risk-adjusted discount rate

- Certainty equivalent approach to valuation, where risk adjusted cash flows, termed certainty equivalent cash flows, are discounted at the riskfree rate;

- Adjusted Present Value (APV) approach, which consists of valuing a business without the effects of debt first, and then consider the effects of borrowing. This approach was first boarded by Modigliani and Miller [13] with the isolation of 
the tax benefits from borrowing, but the APV in its current form was present in [14];

- Valuation based on excess returns on each investment.

In stock valuation, the dividend discount model was arguably first mentioned in Williams [15], where the present value concept was connected to the stock's dividends. Williams also drew a distinction between valuing mature and growth companies in [15]. The value of stock with perpetual growth was derived in [16], but it was Gordon who popularized the model in subsequent articles and a book, giving it the title of the Gordon growth model [17]. Due to the non-realistic property of a single perpetual dividend growth, the two stage (and multi-stage) model was devised in [18] - an extensive categorization of multi-stage models is provided in [19]. The $\mathrm{H}$ model, a two stage growth model where the first stage has a linearly descending growth until the stable (constant) growth figure of the second stage, was devised in [20].

The valuation of companies that pay no dividends due to reinvestment was analyzed in [21] (based on expected dividend payout when the growth rate declines). Fama\&French [22] noted that dividend yields vary much more than dividends, and Foerster\&Sapp [23] analyzed a long time period (from 1871 to 2003) and found that the dividend discount model does a good job explaining the main variations in the S\&P 500 index, though there were systematic differences over time in how investors valued future dividends.

The decline in the average level of dividends paid was analyzed in [22], where it was concluded that today's market portfolio is mostly made of high growth firms and that firms became less likely to pay dividends, as dividend paying firms went from $66,5 \%$ in 1978 to $20,8 \%$ in 1999 . The work in [24], [25], [26] and [27] tried to explain the decline in dividends over time, attributing it to a variety of factors. The fact remained that the gap between dividends paid and potential dividends did increase over time, posing a challenge to the use of dividend discount models. The fix to the posed problem would be to replace dividends with potential dividends in the dividend discount model. Potential dividends can be estimated by three variants:

- Stock buyback as dividends: the work in [28] presents the modified dividend payout including stock buybacks, and argues that it works well in explaining the market prices of companies that return cash over regular intervals via stock buybacks

- Free Cash Flow to Equity model: the publication of Hagstrom [29] describes how Warren Buffet argued that investors should value companies based on its "owner's earnings", which were defined as the cash flows left after capital expenditures and working capital needs.

- Earnings Model: The model of discounting earnings or variants of earnings is discussed in [30] and [31], where a relationship between value and earnings is established. The publication of [32] argued that GAAP (Generally Accepted Accounting Principles) earnings could be substituted for dividends in equity valuation, as long as analysts would reduce future earnings and book value to reflect dividend payments. All these models were prone to double-counting ([32] described that "discounting earnings as if they were cash flows paid out to stockholders while also counting the growth that is created by reinvesting those earnings will lead to the systematic overvaluation of stocks"), something that was discussed in [33].

Nowadays, probably the model with more widespread use is the FCFE / FCFF (Free Cash Flow to Equity and Free Cash Flow to Firm) model. For simplification purposes, we will focus on the FCFE model, which basically is the FCF model's version for the potential dividends.

The question however of using potential dividends versus real dividends endures, and care must be taken when dividends are not distributed, but rather withheld by the company. Since the company might not obtain returns equal to those available in the market for the same level of risk, this paper quantifies the differences in retained cash build-up so that investors know how much to expect in future dividend payouts.

The paper is structured as follows: in section II we discuss the need for the calculating the correction factor to amend the differences in cash build-up and in section III we deduce these differences and the correction factor mathematically. Section IV portrays a sensitivity analysis alongside some practical examples and Section V concludes.

\section{NEED FOR THE CORRECTION FACTOR}

The yearly FCFE can be dealt with in many ways; it can be distributed as dividends (or stock buybacks); invested in a project or invested in the market/ bank (or even shelved) to provide liquidity for future events. All these options are valid, but when valuing a company based on projected FCFE, we need to make sure of what we are doing.

When we consider growth from reinvesting the retained part of the FCFE, we must take care and account these earnings a separate way; FCFE must be calculated from operational income; the financial gains from reinvestments must not be included in the FCFE in order to avoid double counting. Note however that the shareholders expect to receive this money sooner or later, and while it's in the hands of the company, this money should render a rate of return that rewards appropriately the level of risk inherent to the way it is used, let's call it return on investment $r_{i}$.

Usually, many financial projections make the assumption that the retained portion of the FCFE will yield (at least) the standard cost of equity $r_{e}$, but that might not be the case - and as such, some valuation corrections need to occur when we value a company based on FCFE. In fact, differences between shareholder's expectations and reality can be significant, enough to drive the 
company's shares to either a tumble or rise. It is thus crucial to have an idea of the company's return on investment $r_{i}$ on its withheld portion of the FCFE, and compare it to the market's expectation on return on equity.

We will derive the main formula to calculate the return difference, and perform some sensitivity analysis. As main assumptions for this paper, we assume that the mean retention ratio of the $\mathrm{FCFE} \mathrm{rr}_{\mathrm{FCFE}}$ from previous years will remain constant (note that this retention ratio isn't the normal retention ration of the net income used in finance; the FCFE includes Capital Expenditure, meaning that $\mathrm{rr}_{\mathrm{FCFE}}$ is the retention ratio after performing the necessary reinvestments in the company to promote its future growth). The yearly FCFE is assumed to grow at a rate $\mathrm{g}_{\mathrm{FCFE}}$, the company's $\mathrm{rr}_{\mathrm{FCFE}}$ and $\mathrm{r}_{\mathrm{e}}$ are assumed to remain constant, and all investments with the retained capital are assumed to yield a constant rate $r_{i}$.

The Expected Earnings from Retention EER and Overall Rate Difference ORD will be discussed and mathematically deduced in the next section. The explanation for the EER is quite simple; the EER calculates all reinvestment gains from the retained part of the FCFE and discounts it to the present day (gains of $r_{i}$, discounted at $r_{e}$ ); the ORD will yield the rate difference to the market's earnings expectation on the retained capital, that can be anywhere from negative, zero or positive, for terminal value estimation (without being discounted to the present day - the value isn't pushed back since only at the end of the estimation period can we see what the (average) value for $r_{i}$ was). With the ORD rate, we can effectively compute a Correction Factor CF to the shareholder's valuation using discounted FCFE valuation.

\section{DeRIVATION OF THE OVERALl RATE DiFFERENCE AND CORRECTION FACTOR}

The ORD and the CF are discussed and derived in this section. For valuation purposes, usually an annuity is used, with a calculated FCFE as an initial value, a mean FCFE retention rate $\mathrm{rr}_{\mathrm{FCFE}}$ and an estimated FCFE growth rate $\mathrm{g}_{\mathrm{FCFE}}$. We don't know what the company will do with the FCFE (usually having a great amount of cash available might make managers want to allocate some of it for futile expenses or overpay for an investment), but we can calculate the shareholder's expectations on the return from that withheld portion of the FCFE, assuming that the money is effectively invested on the market, and getting a return equivalent to the investment's risk $r_{i}$ (note that the shareholder's overall expected return on their invested capital is $r_{e}$, which is usually bigger than the market's return $r_{m}$ if the company has a beta> 1 compared to the market).

Before deriving the equations for EER and ORD, it's useful to remember that an annuity with growth $\mathrm{g}$ discounted at rate $r$ is calculated as ( $\mathrm{P}$ is the initial value):

$$
A=\frac{P}{r-g}\left[1-\left(\frac{1+g}{1+r}\right)^{n}\right]
$$

In the case of $\mathrm{r}=\mathrm{g}$, we have $A=\sum_{i=1}^{n} \frac{P}{1+r}=\frac{n P}{1+r}$
Let us define DICYF as the Discounted Interest from Current Year's FCFE, which represents the total interest that the withheld FCFE in year $t$ will yield up until year $n$, discounted to year $t$ at $r_{e}$, when used in an application that renders $r_{i}$ interest. Using equation (1) we arrive at:

$$
\begin{aligned}
\operatorname{DICYF}\left(r_{e}, r_{i}, n, t\right) & { } \frac{\mathrm{rr}_{F C F E} \times \mathrm{r}_{\mathrm{i}} \times \mathrm{FCFE}_{\mathrm{t}}}{\mathrm{r}_{\mathrm{e}}-r_{i}} \\
& \times\left[1-\left(\frac{1+r_{i}}{1+\mathrm{r}_{\mathrm{e}}}\right)^{n-t}\right]
\end{aligned}
$$

If $r_{\mathrm{e}}=\mathrm{r}_{\mathrm{i}}$, then we can rewrite it as:

$$
\operatorname{DICYF}\left(r_{e}, n, t\right)=\frac{(n-t) \times r r_{F C F E} \times \mathrm{r}_{\mathrm{e}} \times \mathrm{FCFE}_{\mathrm{t}}}{1+\mathrm{r}_{\mathrm{e}}}
$$

With

$$
\mathrm{FCFE}_{\mathrm{t}}=\mathrm{FCFE}_{1} \times\left(1+g_{F C F E}\right)^{t-1}
$$

(e.g. with $\mathrm{FCFE}=100, \mathrm{r}_{\mathrm{e}}=\mathrm{r}_{\mathrm{i}}=10 \%, \mathrm{rr}_{\mathrm{FCFE}}=100 \%$ and $\mathrm{n}$ $\mathrm{t}=2$, we would have $\left.D I C Y F=\frac{10}{1,1}+\frac{11}{1,1^{2}}=2 \times \frac{10}{1,1}=18,2\right)$.

To compute the EER, we have (for the case $r_{e}=r_{i}$ ):

$\operatorname{EER}\left(r_{e}, n, t\right)=\sum_{t=1}^{n-1} \frac{\operatorname{DICYF}\left(r_{e}, n, t\right)}{\left(1+r_{e}\right)^{t}}$
$=\sum_{t=1}^{n-1} \frac{(n-t) \times r r_{F C F E} \times \mathrm{r}_{\mathrm{e}} \times \mathrm{FCFE}_{\mathrm{t}}}{\left(1+r_{e}\right)^{t+1}}=$
$=\sum_{t=1}^{n-1} \frac{(n-t) \times r r_{F C F E} \times \mathrm{r}_{\mathrm{e}} \times \mathrm{FCFE}_{1} \times\left(1+g_{F C F E}\right)^{t-1}}{\left(1+r_{e}\right)^{t+1}}$
$=r r_{F C F E} \times \mathrm{r}_{\mathrm{e}} \times \mathrm{FCFE}_{1} \times \sum_{t=1}^{n-1} \frac{(n-t) \times\left(1+g_{F C F E}\right)^{t-1}}{\left(1+r_{e}\right)^{t+1}}$

Or in the case that $\left(\mathrm{r}_{\mathrm{e}} \neq \mathrm{r}_{\mathrm{i}}\right)$ :

$$
\begin{aligned}
E E R\left(r_{e}, r_{i}, n, t\right)= & \sum_{t=1}^{n-1} \frac{D I C Y F\left(r_{e}, r_{i}, n, t\right)}{\left(1+r_{e}\right)^{t}} \\
& =\frac{r r_{F C F E} \times \mathrm{r}_{\mathrm{i}} \times \mathrm{FCFE}_{1}}{\mathrm{r}_{\mathrm{e}}-r_{i}} \\
& \times \sum_{t=1}^{n-1}\left[\left(1+g_{F C F E}\right)^{t-1}\right. \\
& \left.\times \frac{\left.1-\left(\frac{1+r_{i}}{1+\mathrm{r}_{\mathrm{e}}}\right)^{n-t}\right]}{\left(1+r_{e}\right)^{t}}\right] \\
& =\frac{r r_{F C F E} \times \mathrm{r}_{\mathrm{i}} \times \mathrm{FCFE}}{\left(1+\mathrm{r}_{\mathrm{e}}\right)^{n}} \\
& \times \sum_{t=1}^{n-1}\left[\left(1+g_{F C F E}\right)^{t-1}\right. \\
& \left.\times \frac{\left.1-\left(1+\mathrm{r}_{\mathrm{i}}\right)^{n-t}\right]}{1-\left(1+\mathrm{r}_{\mathrm{i}}\right)}\right]
\end{aligned}
$$

With the previous formula in mind, we can derive the rate difference (instead of overall value) of the final value (without pushing back in time). Assuming the variable interest as (from EER): 


$$
\begin{aligned}
\text { Interest }\left(g_{F C F E},\right. & \left.n, \mathrm{r}_{\mathrm{i}}\right) \\
& =\mathrm{r}_{\mathrm{i}} \\
& \times \sum_{t=1}^{n-1}\left[\left(1+g_{F C F E}\right)^{t-1}\right. \\
& \left.\times \frac{\left.1-\left(1+\mathrm{r}_{\mathrm{i}}\right)^{n-t}\right]}{1-\left(1+\mathrm{r}_{\mathrm{i}}\right)}\right] \\
& =\sum_{t=1}^{n-1}\left[\left(1+g_{F C F E}\right)^{t-1} \times\left(1+\mathrm{r}_{\mathrm{i}}\right)^{n-t}\right. \\
& -1]
\end{aligned}
$$

We arrive at ORD by subtracting the expected interest of $r_{e}$ from the obtained interest of $r_{i}$ :

$$
\begin{aligned}
\text { ORD }\left(g_{F C F E}, n, \mathrm{r}_{\mathrm{e}}\right. & \left., \mathrm{r}_{\mathrm{i}}\right) \\
& =\text { Interest }\left(g_{F C F E}, n, \mathrm{r}_{\mathrm{i}}\right) \\
& - \text { Interest }\left(g_{F C F E}, n, \mathrm{r}_{\mathrm{e}}\right) \\
& =\sum_{t=1}^{n-1}\left[\left(1+g_{F C F E}\right)^{t-1}\right. \\
& \left.\times\left(\left(1+\mathrm{r}_{\mathrm{i}}\right)^{n-t}-\left(1+\mathrm{r}_{\mathrm{e}}\right)^{n-t}\right)\right]
\end{aligned}
$$

As we can observe from the above formula, ORD depends on 4 variables and not 3 (we can't replace $r_{i}$ and $r_{e}$ with $r_{i}-r_{e}$, due to compound interest). In the next section we will perform some sensitivity analysis on the formula.

The Correction Factor CF that the shareholders must apply (add) to the discounted FCFE valuation is given by:

$$
C F=r r_{F C F E} \times \mathrm{FCFE}_{1} \times O R D\left(g_{F C F E}, n, \mathrm{r}_{\mathrm{e}}, \mathrm{r}_{\mathrm{i}}\right)
$$

Thus being, if a $r_{e}$ of $10 \%$ was expected and a real average $r_{i}$ of $11 \%$ was effectively verified, than the company value effectively increase by $\mathrm{CF}$ (which is a positive value). On the other hand, if we had a $r_{i}$ of $9 \%$ for $\mathrm{a}_{\mathrm{e}}$ of $10 \%$, than the shareholders' expectations will have to be lowered by $\mathrm{CF}$ (which in this case will be negative).

\section{SENSITIVITY ANALYSIS}

In this section we will perform a sensitivity analysis on the ORD formula, in order to assess the true deviation rates from the shareholders' expected cash build-up in the company. Several examples are shown, in order to "feel" the non-linearity of the ORD formula. All examples have a fixed $r_{e}$ and variable $g_{\text {fffe }}, n$ and $r_{i}$.

In Table I., we can see several return differences from fixed $r_{e}=10 \%$ and $r_{i}=9 \%$ values. Since $r_{i}$ is the yearly rate of return, the return deviation for $n=2$ is $-1 \%$ as expected (the first FCFE is liberated and partially retained at the end of the first year, and its application rendering $r_{i}$ will yield a rate difference of $-1 \%$ compared to the case of it rendering $r_{e}$, at the end of year 2). The value for $n=3$ is a bit more complicated to explain; the rate loss is higher due to the rate loss of $1 \%$ in the previous year, added to the rate loss of around $2 \%$ at the end of $n=2$ (due to the sum of the retained FCFE from $n=1$ and $n=2$ ), adding up to a loss of around $3 \%$. The loss is greater than just the $3 \%$ due to compounded interest gains, that is losing $1 \%$ by being applied at a rate $r_{i}=9 \%$ instead of a rate of $r_{e}=10 \%$. In table I we can also assess the importance of a growing/ diminishing FCFE in assessing the rate difference.

TABLE I. FIXED $R_{\mathrm{E}}=10 \%$ AND $\mathrm{R}_{\mathrm{I}}=9 \%$

\begin{tabular}{|r|r|r|r|r|r|r|r|r|r|}
\hline gffe $\backslash \mathrm{n}$ & 2 & 3 & 4 & 5 & 6 & 7 & 8 & 9 & 10 \\
\hline$-3 \%$ & $-1,00 \%$ & $-3,16 \%$ & $-6,66 \%$ & $-11,71 \%$ & $-18,55 \%$ & $-27,44 \%$ & $-38,69 \%$ & $-52,63 \%$ & $-69,65 \%$ \\
$0 \%$ & $-1,00 \%$ & $-3,19 \%$ & $-6,79 \%$ & $-12,04 \%$ & $-19,23 \%$ & $-28,67 \%$ & $-40,74 \%$ & $-55,84 \%$ & $-74,45 \%$ \\
$3 \%$ & $-1,00 \%$ & $-3,22 \%$ & $-6,91 \%$ & $-12,37 \%$ & $-19,93 \%$ & $-29,98 \%$ & $-42,94 \%$ & $-59,33 \%$ & $-79,72 \%$ \\
$6 \%$ & $-1,00 \%$ & $-3,25 \%$ & $-7,04 \%$ & $-12,72 \%$ & $-20,67 \%$ & $-31,35 \%$ & $-45,30 \%$ & $-63,12 \%$ & $-85,52 \%$ \\
\hline
\end{tabular}

\begin{tabular}{|c|c|c|c|c|c|c|c|c|c|}
\hline & \multicolumn{3}{|c|}{$\mathrm{r}=9 \%$} & \multicolumn{3}{|c|}{$r_{i}=11 \%$} & \multicolumn{3}{|c|}{$r_{i}=12 \%$} \\
\hline gfffe $\backslash n$ & 2 & 6 & 10 & 2 & 6 & 10 & 2 & 6 & 10 \\
\hline$-3 \%$ & $-1,00 \%$ & $-18,55 \%$ & $-69,65 \%$ & $1,00 \%$ & $19,04 \%$ & 73,49\% & $2,00 \%$ & $38,58 \%$ & $151,01 \%$ \\
\hline $0 \%$ & $-1,00 \%$ & $-19,23 \%$ & $-74,45 \%$ & $1,00 \%$ & $19,72 \%$ & $78,46 \%$ & $2,00 \%$ & $39,96 \%$ & $161,13 \%$ \\
\hline $3 \%$ & $-1,00 \%$ & $-19,93 \%$ & $-79,72 \%$ & $1,00 \%$ & $20,44 \%$ & $83,91 \%$ & $2,00 \%$ & $41,40 \%$ & $172,24 \%$ \\
\hline $6 \%$ & $-1,00 \%$ & $-20,67 \%$ & $-85,52 \%$ & $1,00 \%$ & $21,19 \%$ & $89,91 \%$ & $2,00 \%$ & $42,90 \%$ & $184,43 \%$ \\
\hline
\end{tabular}

Table II has variable $r_{i}$ for a fixed $r_{e}=10 \%$. In this example, we can see the case for $r_{i}=9 \%$ (similar to table I), and cases for $r_{i}=11 \%$ and $r_{i}=12 \%$. Note the case for $n=2$, with the rate difference of 1 year being equal to $r_{i}-r_{e}$. For the case of $r_{i}>r_{e}$, the rate is positive, yielding an excess gain rate. Note that the overall rate gains can be as high as

\begin{tabular}{|c|c|c|c|c|c|c|c|c|c|}
\hline & \multicolumn{3}{|c|}{$r_{i}=9 \%$} & \multicolumn{3}{|c|}{$r=11 \%$} & \multicolumn{3}{|c|}{$r=12 \%$} \\
\hline gffife $\backslash n$ & 4 & 5 & 6 & 4 & 5 & 0 & 4 & 5 & 6 \\
\hline$-1 \%$ & $-6,75 \%$ & $-11,93 \%$ & $-19,00 \%$ & $6,83 \%$ & $12,16 \%$ & $19,49 \%$ & $13,75 \%$ & $24,55 \%$ & $39,49 \%$ \\
\hline $0 \%$ & $-6,79 \%$ & $-12,04 \%$ & $-19,23 \%$ & $6,87 \%$ & $12,27 \%$ & $19,72 \%$ & $13,83 \%$ & $24,77 \%$ & $39,96 \%$ \\
\hline $1 \%$ & $-6,83 \%$ & $-12,15 \%$ & $-19,46 \%$ & $6,92 \%$ & $12,38 \%$ & $19,96 \%$ & $13,92 \%$ & $25,00 \%$ & $40,43 \%$ \\
\hline $2 \%$ & $-6,87 \%$ & $-12,26 \%$ & $-19,69 \%$ & $6,96 \%$ & $12,49 \%$ & $20,20 \%$ & $14,00 \%$ & $25,22 \%$ & $40,91 \%$ \\
\hline
\end{tabular}
$184 \%$ for $\mathrm{n}=10$, with $\mathrm{r}_{\mathrm{i}}=12 \%$ and $\mathrm{g}_{\mathrm{fcfe}}=6 \%$ ! table III and IV also have a fixed $r_{\mathrm{e}}=10 \%$, performing a sensitivity

\begin{tabular}{|c|c|c|c|c|c|c|c|c|c|}
\hline & \multicolumn{3}{|c|}{$r_{i}=7 \%$} & \multicolumn{3}{|c|}{$r i=13 \%$} & \multicolumn{3}{|c|}{$r=16 \%$} \\
\hline gicfe $\mid n$ & 2 & 6 & 10 & 2 & 6 & 10 & 2 & 6 & 10 \\
\hline$-3 \%$ & $-3,00 \%$ & $-54,23 \%$ & $-198,21 \%$ & $3,00 \%$ & $58,62 \%$ & $232,78 \%$ & $6,00 \%$ & $121,92 \%$ & $505,75 \%$ \\
\hline $0 \%$ & $-3,00 \%$ & $-56,23 \%$ & $-212,10 \%$ & $3,00 \%$ & $60,71 \%$ & $248,23 \%$ & $6,00 \%$ & $126,19 \%$ & $538,40 \%$ \\
\hline $3 \%$ & $-3,00 \%$ & $-58,32 \%$ & $-227,38 \%$ & $3,00 \%$ & $62,89 \%$ & $265,19 \%$ & $6,00 \%$ & $130,64 \%$ & $574,16 \%$ \\
\hline $6 \%$ & $-3,00 \%$ & $-60,49 \%$ & $-244,20 \%$ & $3,00 \%$ & $65,16 \%$ & $283,79 \%$ & $6,00 \%$ & $135,27 \%$ & $613,35 \%$ \\
\hline
\end{tabular}
analysis with different values, with smaller growth rate for FCFE (Table III), and larger values for $r_{i}$ (Table IV).

\begin{tabular}{|c|c|c|c|c|c|c|c|c|c|}
\hline & \multicolumn{3}{|c|}{$r_{i}=8 \%$} & \multicolumn{3}{|c|}{$r i=10 \%$} & \multicolumn{3}{|c|}{$r i=11 \%$} \\
\hline gfcfe $\ n$ & 4 & 5 & 6 & 4 & 5 & 6 & 4 & 5 & 6 \\
\hline$-1 \%$ & $-6,66 \%$ & $-11,70 \%$ & $-18,52 \%$ & $6,75 \%$ & $11,93 \%$ & $19,00 \%$ & $13,58 \%$ & $24,09 \%$ & $38,49 \%$ \\
\hline $0 \%$ & $-6,70 \%$ & $-11,81 \%$ & $-18,74 \%$ & $6,79 \%$ & $12,04 \%$ & $19,23 \%$ & $13,66 \%$ & $24,31 \%$ & $38,95 \%$ \\
\hline $1 \%$ & $-6,74 \%$ & $-11,92 \%$ & $-18,97 \%$ & $6,83 \%$ & $12,15 \%$ & $19,46 \%$ & $13,74 \%$ & $24,53 \%$ & $39,42 \%$ \\
\hline $2 \%$ & $-6,79 \%$ & $-12,03 \%$ & $-19,20 \%$ & $6,87 \%$ & $12,26 \%$ & $19,69 \%$ & $13,83 \%$ & $24,75 \%$ & $39,89 \%$ \\
\hline
\end{tabular}

TABLE II. SENSITIVITY ANALYSIS WITH FIXED $\mathrm{R}_{\mathrm{E}}=10 \%$, PART A

In table $\mathrm{V}$ and $\mathrm{VI}$, sensitivity analysis is performed re values of $9 \%$ and $11 \%$ respectively, with similar differences to table III, for direct comparison. Note that the differences are almost negligible.

TABLE III. SENSITIVITY ANALYSIS WITH FIXED $R_{\mathrm{E}}=10 \%$, PART B

TABLE IV. SENSITIVITY ANALYSIS WITH FIXED $R_{\mathrm{E}}=10 \%$, PART C

TABLE V. SENSITIVITY ANALYSIS WITH FIXED $R_{E}=9 \%$ 
TABLE VI. SENSITIVITY ANALYSIS WITH FIXED $R_{\mathrm{E}}=11 \%$

\begin{tabular}{|c|c|c|c|c|c|c|c|c|c|}
\hline & \multicolumn{3}{|c|}{$r=10 \%$} & \multicolumn{3}{|c|}{$r_{i}=12 \%$} & \multicolumn{3}{|c|}{$r=13 \%$} \\
\hline gffefe $\backslash n$ & 4 & 5 & 6 & 4 & 5 & 6 & 4 & 5 & \\
\hline$-1 \%$ & $-6,83 \%$ & $-12,16 \%$ & $-19,49 \%$ & $6,92 \%$ & $12,39 \%$ & $20,00 \%$ & $13,92 \%$ & $25,02 \%$ & 40,5 \\
\hline $0 \%$ & $-6,87 \%$ & $-12,27 \%$ & $-19,72 \%$ & $6,96 \%$ & $12,50 \%$ & $20,23 \%$ & $14,01 \%$ & $25,25 \%$ & 40,98 \\
\hline $1 \%$ & $-6,92 \%$ & $-12,38 \%$ & $-19,96 \%$ & $7,00 \%$ & $12,62 \%$ & $20,47 \%$ & $14,09 \%$ & $25,47 \%$ & 41,479 \\
\hline $2 \%$ & $-6,96 \%$ & $-12,49 \%$ & $-20,20 \%$ & $7,04 \%$ & $12,73 \%$ & $20,71 \%$ & $14,18 \%$ & $25,70 \%$ & 41,95 \\
\hline
\end{tabular}

With these rates in mind, we must correct for the shareholders' expectations. The discounted FCFE valuation assumes that with-held cash will render the cost of equity $r_{e}$. If this is the case, the correction factor is 0 ; otherwise we will need to employ the $\mathrm{CF}$, since the free cash the company will have in the end will be different from the shareholders' expected value.

To correct the valuation, we simply take our discounted FCFE valuation value at the end of the exercise, and add the $\mathrm{CF}$ to that valuation number. From table VI, with a $\mathrm{r}_{\mathrm{i}}=13 \%, \mathrm{n}=5$ and $\mathrm{g}_{\text {fcfe }}=2 \%$, we have a ORD $=25,7 \%$. The $\mathrm{CF}$ will thus be $25,7 \%$ multiplied by the original retained FCFE, $\quad r r_{F C F E} \times F C F E_{1} \quad\left(\mathrm{FCFE}\right.$ retention rate $\mathrm{rr}_{\mathrm{FCFE}}$ assumed constant). In this particular case, the shareholders would be happy to know that the company would be worth $C F=25,7 \% \times r r_{F C F E} \times F C F E_{1}$ more than their expectations.

Note that the previous example is performed at the end of the period (when $r_{i}$ can effectively be calculated), but we can also use this formula to account for any deviation to $r_{e}$ beforehand. In that case, from table VI with $r_{e}=11 \%$, $\mathrm{n}=5$ and $\mathrm{g}_{\mathrm{fcfe}}=2 \%$, we can account for an investment return between $\mathrm{r}_{\mathrm{i}}=10 \%$ and $\mathrm{r}_{\mathrm{i}}=12 \%$, with ORD of $-12,49 \%$ and $12,73 \%$ respectively. Pushing back these ORD $n=5$ years at $r_{e}=10 \%$, we have discounted ORD values $\left(\frac{O R D}{1,1^{5}}\right)$ of -7 , $76 \%$ and $7,9 \%$, that when multiplied by $r r_{F C F E} \times$ $F C F E_{1}$ will subtract and add to the initial estimate respectively, yielding a valuation estimation window for forecasting.

\section{CONCLUSION}

In this paper we were able to quantify the rate differences between investing the retained part of FCFE at the expected rate $r_{e}$ (cost of equity expected by the shareholders) and the real investment rate obtained from using the retained capital at a rate $r_{i}$. These differences may reach very significant values for companies that withheld dividends and use the discounted FCFE valuation method. A correction factor of the company's valuation was calculated and employed in order to adjust the retention's rate gain/loss from the expected rate to the real rate.

\section{REFERENCES}

[1] R. H. Parker, "Discounted cash flow in historical perspective," Journal of Accounting Research, vol. 6, pp. 58-71, 1968

[2] S Stevin, Tables of Interest, 1582.

[3] A. M. Wellington, The Economic Theory if the Location of Railways, Wiley, New York, 1887
[4] A. V. Bohm-Bawerk, Recent Literature on Interest, Macmillan, 1903

[5] A. Marshall, Principles of Economics, Macmilllan, London, 1907

[6] W. O. Pennell, "Present worth calculations in engineering studies," Journal of the Association of Engineering Societies, 1914.

[7] I. Fisher, The Rate of Interest, Macmillan, New York, 1907.

[8] I. Fisher, The Theory of Interest, Macmillan, New York, 1930.

[9] K. E. Boulding, "The theory of a single investment," Quarterly Journal od Economics, vol. 49, pp. 479-494, 1935.

[10] J. M. Keynes, The General Theory of Employment, Macmillan, London, 1936.

[11] P. Samuelson, "Some aspects of the pure theory of capital," Quarterly, Journal of Economics, vol. 51, pp. 469-496, 1937.

[12] Dean, Joel, Capital Budgeting, Columbia University Press, New York, 1951.

[13] F. Modigliani and M. Miller, "Corporate income taxes and the cost of capital: a correction", American Economic Review, vol. 53, pp. 433-443, 1963.

[14] S. Myers, "Interactions in corporate financing and investment decisions-implications for capital budgeting," Journal of Finance, vol. 29, pp. 1-25, 1974.

[15] J. B. Williams, Theory of Investment Value, Fraser Publishing, 1938.

[16] D. Durand, "Growth stcks and the St. Petersburg paradox," Journal do Finance, vol. 12, pp. 348-363, 1957.

[17] M. J. Gordon, The Investment, Financing and Valuation of the Corporation, Homewood, Illinois: Richard D. Irwin Inc, 1962.

[18] Bernstein, Proprietary two-stage dividend discount model used by the investment firm Sanford Bernstein, 1967.

[19] A. Damodaran, Damodaran on Valuation, John Wiley, New York, 1994.

[20] R. J. Fuller and C. Hsia, "A simplified common stock valuation model," Financial Analysts Journal, vol. 40, pp. 49-56, 1984.

[21] R. O. and P. L. Davis, "Valuation model bias and the scale structure of dividend discount returns," Journal of Finance, vol. 37, pp. 565-573, 1981.

[22] E. F. Fama and K. R. French, "Disappearing dividends: Changing firm characteristics or lower propensity to pay?" Journal of Financial Economics, vol. 60, pp. 3-44, 2001.

[23] S. R. Foerster and S. G, Sapp, "Dividends and stock valuation: A study of the nineteenth to the twenty-first century," Working Paper, University of Western Ontario, 2005.

[24] H. DeAngelo, L. DeAngelo, and D. Skinner, "Are dividends disappearing? Dividend concentration and the consolidation of earnings," Journal of Financial Economics, vol. 72, pp. 425-456, 2004.

[25] G. Hoberg and N. R. Prabhala, "Disappearing dividends: The importance of idiosyncratic risk and the irrelevance of catering," Working Paper, University of Maryland, 2005.

[26] M. Baker and J. Wurgler, "Appearing and disappearing dividends: The link to catering incentives," Journal of Financial Economics, vol. 73, pp. 271-288, 2004a.

[27] M. Baker and J. Wurgler, "A catering theory of dividends," Journal of Finance, vol. 59, pp. 1125-1165, 2004b.

[28] A. Damodaran, Damodaran on Valuation, 2nd Ed. John Wiley and Sons, New York, 2006.

[29] R. Hagstrom, The Warren Buffett Way, John Wiley, New York, 2004.

[30] J. Ohlson,"Earnings, book values and dividends in security valuation," Contemporary Accounting Research, vol. 11, pp. 661687, 1995.

[31] G. Feltham and J. Ohlson, "Valuation and clean surplus accounting of operation and financial activities," Contemporary Accounting Research, vol. 11, pp. 689-731, 1995.

[32] S. Penman and T. Sougiannis, "The dividend displacement property and the substitution of anticipated earnings for dividends in equity valuation," The Accounting Review, vol. 72, pp. 1-21, 1997.

[33] J. Glassman and K. Hassett, "Dow 36,000: The new strategy for profiting from the coming rise in the stock market," Three Rivers Press, 2000. 


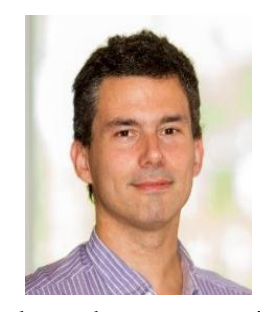

João Carlos. M. Silva received the BSc and MSc degree for Aerospace Engineering from Instituto Superior Técnico (IST) - Lisbon Technical University, (1995-2000). From 20002002 he worked as a business consultant in strategic management in McKinsey\&Company. From 2002 to 2006 he undertook his PhD in telecommunications at IST, integrated in $3 \mathrm{EU}$ projects (Seacorn, B-Bone e C-Mobile), having been the representative of the university. Since 2006, he has been working on computer networks, as an assistant professor in Instituto Superior das Ciências do Trabalho e da Empresa (ISCTE). Recently, he finished his MBA at ISEG (Instituto Superior de Economia e Gestão), and aims to work on technological management in the near future. Email: joao.silva@iscte.pt

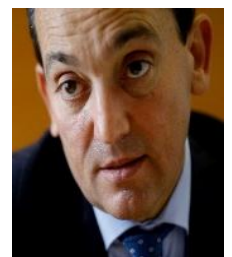

José Azevedo Pereira is a full Professor of Finance, at Universidade de Lisboa, ISEG Instituto Superior de Economia e Gestão. He holds a PhD from the Manchester Business School and an MBA, from ISEG. Besides his academic career he has held top executive positions in several companies. During seven years he led the Portuguese Tax and Customs Authority, where he was Director-General and Chairman of the Board. Email: jpereira@iseg.ulisboa.pt 